\title{
Enhancing Inquiry-Based Language Learning With Educational Digital Library
}

\author{
Hsin-Lin Lu (Corresponding author) \\ Department of English Language and Literature, Fu Jen Catholic University \\ 510 Zhungzheng Rd, Xinzhuang Dist., New Taipei City, 24205 Taiwan \\ Tel: 886-2-2905-2000Ｅ-mail: hsinlinlu@gmail.com
}

Cooper Singman

Department of Applied Foreign Languages, Tatung University

40, Sec. 3, Zhongshan N. Rd., Taipei City 104, Taiwan

Tel: 886-2-2182-2928 \#6802Ｅ-mail: cooper@ttu.edu.tw

Received: August 24, 2014 Accepted: September 9, 2014 Published: September xx, 2014

doi:10.5296/jet.v2i1.6199 URL: http://dx.doi.org/10.5296/jet.v2i1.6199

\begin{abstract}
As the amount of information available in online digital libraries increases exponentially, questions arise concerning the most productive way to use that information to advance learning. This study investigated the value of an organized educational digital library in supporting and improving EFL students' inquiry learning process. Ninety-eight participants in two groups were compared in their learning performance. One approach used traditional open access to information while the other used an online digital library to accessing information during their inquiry-based information search process. A One-Way ANCOVA and an Independent-Samples t-test were used to examine the two groups on their English reading comprehension and learning attitudes. Results indicated students who used structured search strategies with digital libraries had higher learning performance in English reading comprehension. Digital libraries can also increase the quality of learning process and enhance the students' learning with more positive attitude.
\end{abstract}

Keywords: educational digital library, inquiry-based learning, EFL, English reading comprehension, learning attitudes 


\section{Introduction}

Over the last decade, computer-assisted language learning (CALL) has represented an alternative approach for EFL learners and instructors on maintaining students' interest in languages. Such changes have provide students an excellent opportunity for autonomous, interactive, collaborative, and multi-sensory learning. However, while teachers and students benefit from an abundance of online resources, they are faced with the challenge of discovering the most useful content. Even the most popular search engines like Google and Yahoo return an overwhelming amount of results that are not targeted at solving the problem at hand. Foreign language learners are especially challenged when it comes to deciding which content is the most accurate, truthful or authentic, and which content is most appropriate to solving their problems. Searches within digital libraries, often provide more authoritative, organized, and authentic materials than open access web searches and they can play a crucial role in the quality of the student's inquiry and value of the education (C. M. Chen \& C. C. Chen, 2010).

Instead of simply viewed as another source of information for students, digital libraries should be viewed as resources to guide students to confront the mass of online resources and avoid being overwhelmed by it. Digital libraries can make a significant contribution if they can provide new opportunities for students to engage in manipulating target language information and transforming it into meaningful ways of critical and creative thinking (Bush \& Terry, 1997).

Applying the earlier information seeking theories to the digital libraries experience, Carol Kuhlthau (2010) created the inquiry-based information search process (ISP) model. This ISP model describes thoughts, actions, and feelings in six stages of inquiry: initiation, selection, exploration, formulation, collection, and presentation. The ISP provides insight into how to guide students in the inquiry process by involving identification of a topic and organizing information into a coherent structure in the digital library environment. In order to complete specific assignments through these steps, students need to select a subject area to inspire real investigation and prompt new understanding of their own interests. In other words, digital libraries enable learners to concentrate on constructing new knowledge in the stages of the inquiry process by establishing a plan, strategically conducting research to collect information, and evaluating the results of the information found to solve the given academic problems, which requires learners to interpret a learning problem based on multiple information sources.

Although a growing body of research highlights the beneficial role of educational digital libraries in variety fields, little is known about the effectiveness of an organized educational digital library in supporting and improving inquiry-based language learning. This study points out the challenge that educators and students face with while utilizing Internet as a teaching tool to support inquiry-based learning. In the practical perspective, the findings of this study provide an alternative model for how to integrate digital libraries into learning and teaching process. With better information about the process of inquiry-based learning, teachers can design and implement appropriate multimedia technology to move from teacher-directed instruction to student-centered exercises, which can engage learners to learn traditional school subject and generate the concept to gain a new perspective on their own life experiences. 
By gathering the data from 98 college students in Taiwan, this study provides an alternative model for how to integrate technology with the learning process to engage EFL students to learn more meaningfully. This study would try to answer the following research questions:

1) Is there any difference on the English reading comprehension scores between the Digital Library group and the Open Access group after controlling for pre-intervention achievement levels?

2) Is there any difference in EFL students' learning attitudes between the Digital Library group and the Open Access group?

\section{Literature Review}

\subsection{The Evolution of Educational Digital Libraries}

Libraries are important institutions that store collections, preserve culture and information, provide information services, and assist academic activities. The principal difference between traditional libraries and digital libraries is that digital libraries offer a greater opportunity for users to retrieve and use information through the Internet which extend the roles and values of traditional libraries (Marchionini \& Maurer, 1995). Digital libraries are complex and advanced distributed information spaces that have proved useful for long-term preservation of information digitization (Russell, 1998) and offered real-time interactive services enable public to easily manage and monitor vast quantities of multimedia data via the Internet (Ferguson \& Bunge, 1997). Their sources can be searched more efficiently than those in physical libraries, and the information they contain can be updated more frequently (Gunn, 2002) which extend the roles and the values of traditional libraries.

Well-designed digital libraries can provide large volume of high-quality educational materials that have been carefully authored for all learners to explore the world around them. Compared to other unmonitored digital resources, digital libraries can equip users to use search engines more effectively (Jayawardana, Hewagamage, \& Hirakawa, 2001) and facilitate better learning (C. M. Chen \& C. C. Chen, 2010). Additionally, with effective use of digital libraries, a user's learning attitude can be changed for the better (Thong, Hong \& Tam, 2004) and become more positive and enthusiastic about the value and the quality of the discovered learning resources (Recker et al., 2005). Although considerable research has focused on the creation and management of digital libraries, only within the last several years, few studies have addressed the effectiveness of digital libraries on educational practices (Leazer, Gilliland-Swetland, \& Borgman, 2000; Sumner \& Marlino, 2004; Goh, Ang, Theng, \& Lim, 2005; Marshall, Chen, Shen, \& Fox, 2006; Chu et al., 2008). Based on this literature survey, educational digital libraries indeed play an increasingly important role in teaching and learning. As we learn more about how users around the world use this technology, and how developers can improve digital libraries to meet users' information needs, the research literature on digital libraries continues to grow.

\subsection{The Role of Digital Libraries in Language Learning}

As online resources are widely used to advance language education recently, questions arise 
concerning the critical disadvantages of Internet while utilizing Internet as a teaching tool to support language learning. This study argues that educational digital libraries are more controlled and structured environments can be a valuable technological tool to support and improve EFL student's English language skills.

$\mathrm{Wu}$ and Witten (2006) pointed out that searching multiple online sources is frustrating and time-consuming. It is hard for EFL teachers to evaluate if the website is a safe and reliable educational environment which has a congenial interface and the accurate use of language. Students may come across unsuitable and inappropriate content by accident when they study on their own. Also, students may not be able to locate appropriate materials that match their language ability. Mikulecky (2007) demonstrated that digital libraries provide a wide range of materials, topics, difficulty levels and sophisticated illustrations for beginning and intermediate level EFL learners to practice English within one's proficiency range. If a learner has control of at least $95 \%$ of words on a page, it will be easier for he or she to guess the meaning of unknown words and foster extensive reading.

Moreover, Hung (2008) argued that students does not pay much attention on verifying the accuracy of online information when surfing English websites. Consequently, surfing English websites does not result in meaningful learning until learners articulate an intention to use that information to do something meaningful. C. M. Chen and C. C. Chen (2010) pointed out that learners can be easily lost in the hyperspace while finding and digesting suitable resources with an overwhelming amount of information. Students may not have the ability to justify the quality of resources that they found on the Iternet. The challenge for students is how to confront the mass of online resources and avoid being overwhelmed by it when searching and selecting online information.

With more reliable, organized, and authoritative resources stored in digital libraries, teachers can access information and turn into meaningful language exercises. Students can be engaged in locating appropriate material, exposing to contemporary language usage, and using proper tools to study independently. Through purposeful searching and browsing of a particular subject, digital libraries can facilitate and tailor the special needs of language learners (Wu \& Witten, 2007). In this way, important skills of critical thinking, problem solving, and creative thinking can be taught and developed along with improving their English language skills in the process of extensive reading, evaluating content of texts, selecting relevant information, and synthesizing materials in the educational digital library environment.

\subsection{Selection of Educational Digital Libraries}

Digital libraries have the potential to change the fundamental aspects of teaching and learning. To reach the goals of formal education, new pedagogical methods should accompany digital libraries as an emerging technology for education (Sharifabadi, 2006). Most importantly, digital libraries should provide a meaningful connection between learning activities and resources. A dozen of educational digital libraries around the world were reviewed to meet the goal of this study and the National Science Digital Library (NSDL) was chosen in the end. The elaboration of selection criteria to arrive at the site is included below. 
A couple of first thoughts on educational digital selection are that the website needs to be stable over a long period of time and it needs to be one of the nationwide educational digital libraries that offers free online materials for education and research. Based on the guidelines of the DLESE Community Review (Kastens, 2005), digital resource collections are required to include the following five elements to inspire confidence among the user: a) scientifically accurate, b) pedagogically effective and well-documented, c) easy to use, d) motivational for learners, and e) robust as digital resources. The NSDL is a large educational digital library, contains the necessary breadth and depth of scientific, pedagogical content and cultural treasures to support learning and teaching in educational settings, which can promote independent, and extensive reading while students are exposing in the vast amount of authentic materials.

The second thing that needs to point out is to investigate how educational digital libraries may support adaptive pedagogical use in EFL learning situations. Although originally, NSDL is a place that created to meet the goal for students and educators to find exceptional education resources in science, technology, engineering, and mathematics, it makes it natural and meaningful to introduce the culture of the target language to EFL learners. Learning a topic that they are interested through the medium of a foreign language can make language learning more interesting and motivational. Furthermore, the materials used in NSDL consist plenty of primary authentic texts produced for native speakers, enable EFL students immersed in the foreign language environment. Therefore, NSDL including extensive materials was chosen to provide cultural context, alternative points of reference, and worldview from target language speaking country which can offer readers the fullest possible set of critical reading experiences.

Third, as Kuhlthau (1997) stated, an effective digital library environment should support learners as they progress through six stages of inquiry, namely: initiation, selection, exploration, formulation, collection, and presentation. For these steps, NSDL can support as a tool to help students to identify a topic, to search information purposefully, to explore a particular topic, and to find the right information amidst a huge amount of digital material. As learners progress through these steps, they can practice focusing on organizing information into a coherent structure and become involved in thinking processes.

\section{Research Method}

\subsection{Participants}

The study was conducted with participants who represent the population of Taiwanese college EFL learners. Two existing classes with 98 freshmen majoring in Applied English were recruited as subjects. They were between 18-21 years old, 78.6 \% of the participants $(\mathrm{N}=77)$ were females, and $21.4 \%$ of the participants $(\mathrm{N}=21)$ were males. In regard to the years students have learned English, majority of the participants (58.2\%) have learned English for 8-10 years. All participants don't have prior experience of using digital library. 


\subsection{Instruments}

\subsubsection{English Reading Comprehension Test}

The test covered five passages with controversial topics were adopted from Lougheed's (2006) "Barron's TOEIC: Test of English for International Communication". Both the pretest and posttest were the same version contains 17 multiple-choice questions. The Cronbach's $\alpha$ for the test was 0.719 , which has reached an acceptable level of reliability.

\subsubsection{Attitude Survey}

At the end of the treatment period, the students in both groups completed a survey that includes demographic questions, attitudes questions and two open-ended questions concerning the total hours students spent locating information and total resources they used for completing the assignments. The survey in this study was integrated from previous studies (Wu \& Witten, 2007; Liaw, 2007; C. M. Chen \& C. C. Chen, 2010), and was re-created by the researcher. The survey was translated from English to Chinese. The Cronbach's $\alpha$ for the questionnaire survey was 0.954, which indicated an excellent consistency across the items that form this scale.

\subsection{Procedures}

The study took place over a six-week period in one semester. The pretest of English reading comprehension was administered to both classes to evaluate the students' pre-intervention achievement levels.

During the intervention period, students in two groups were given different approaches to cultivate inquiry process. They were required to finish tasks in six stages of inquiry: Required, Keywords, Explore, Formulate, Collect, and Present, which was adopted from Kuhlthau's (1997) inquiry-based information search process (ISP) model. In the stage three "Explore", the students in the Digital Library group used an online digital library- NSDL to accessing information while those in the Open Access group used other search engine like Google or Yahoo to search information.

The study was set up using PBworks Wiki as a space to store the links of the resources and hold content (Figure 1). The students in two groups received a short introduction of using PBworks. The content covered three instructional units, Our Modern Lifestyle, Our Changing Diet, and Inventions that were adopted from Anderson's (2007) textbook on "Active Skills for Reading". In order to finish these three projects, students in both groups were free and encouraged to seek and engage with a diverse range of sources of topics and build background knowledge. They were taught to organize their project into six stages of inquiry based on Kuhlthau's model (2004) and post the projects to their own Wiki. The activities were designed to stimulate students to think and learn through the use of the target language. In order to guide but not to control the process of learning, these three units were created as meaningful tasks (Table 1). Both of the Digital Library group and the Open Access group were presented with the same units and received the same assignments. Lastly, both groups participated in post-intervention English reading comprehension tests that took place at the end of semester as well as completed a survey measuring their attitude toward their respective learning activity. 


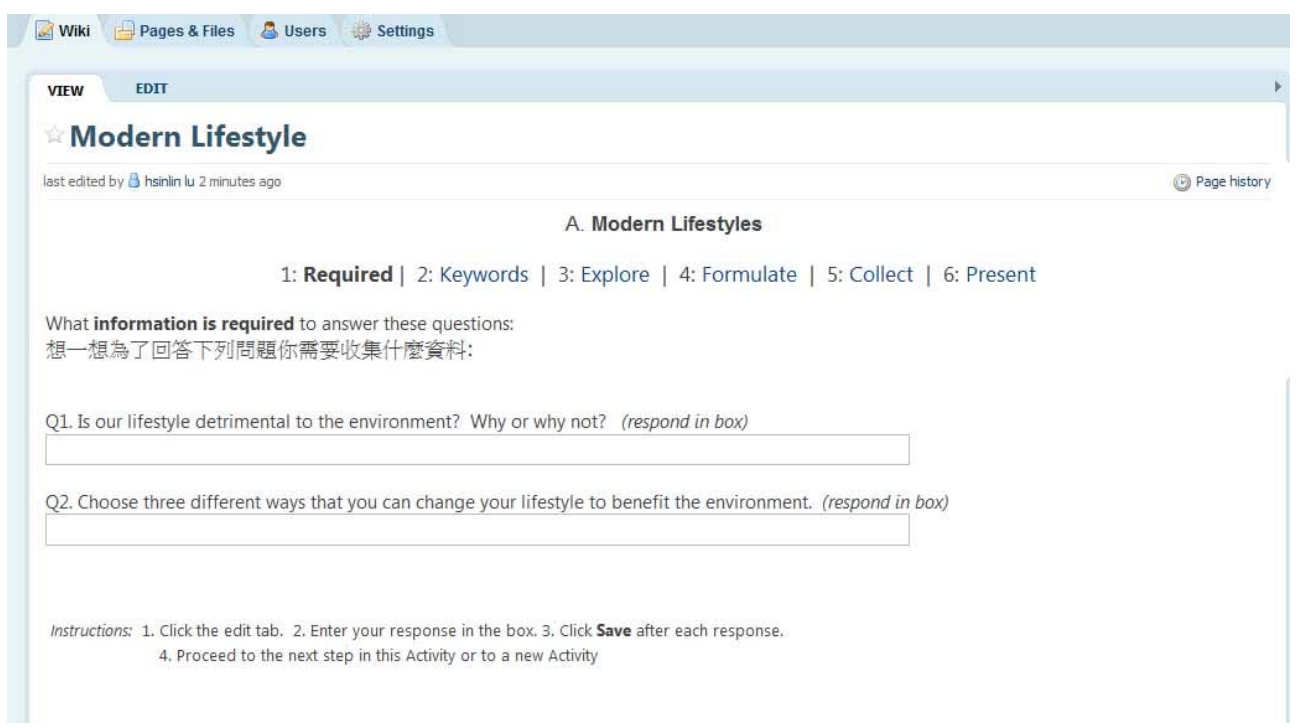

Figure 1. Screenshot of PBworks wiki

Table 1. Detailed descriptions of activities

\begin{tabular}{|c|c|}
\hline Topic & Main Tasks \\
\hline $\begin{array}{l}\text { Week } 1 \text { and 2: } \\
\text { Our Modern } \\
\text { Lifestyle }\end{array}$ & $\begin{array}{l}\text { 1. Do you think that our lifestyle is detrimental to the } \\
\text { environment? Why or why not? } \\
\text { 2. Choose three different ways in which you are interested in } \\
\text { making changes of your lifestyle that will have a beneficial } \\
\text { effect on the environment. }\end{array}$ \\
\hline $\begin{array}{l}\text { Week } 3 \text { and 4: } \\
\text { Our Changing } \\
\text { Diet }\end{array}$ & $\begin{array}{l}\text { 1. Do you believe that "You are what you eat"? Why or why } \\
\text { not. } \\
\text { 2. Do you believe that "A person who doesn't eat meat can not } \\
\text { get enough protein and be healthy"? Why or why not? } \\
\text { 3. List three ways on eating healthier for life. }\end{array}$ \\
\hline $\begin{array}{l}\text { Week } 5 \text { and 6: } \\
\text { Inventions }\end{array}$ & $\begin{array}{l}\text { 1. Choose } 6 \text { of the top } 20 \text { inventions of the } 20^{\text {th }} \text { century and } \\
\text { write } 1 \text { complete sentence that describes how each of your } \\
\text { chosen inventions makes our lives easier. } \\
\text { 2. Choose } 2 \text { inventions from your list of } 6 \text { that you compiled } \\
\text { from the Top } 20 \text { inventions of the } 20^{\text {th }} \text { century. Collect the } \\
\text { information and write } 2 \text { sentences for each that describe the } \\
\text { history of the invention. } \\
\text { 3. Choose an inventor of one of your Top } 6 \text { inventions and } \\
\text { describe, in } 1 \text { paragraph, what drove them to discover their } \\
\text { invention. }\end{array}$ \\
\hline
\end{tabular}




\subsection{Data Analysis}

This study used quantitative measures to gather data from Taiwanese EFL students to analyze the effects of digital libraries on their learning performance and attitude. A One-Way ANCOVA was conducted to examine the two groups on their English reading comprehension. An Independent-Samples t-test was used to test students' learning attitudes toward learning using different approaches.

\section{Results and Discussion}

\subsection{The Influence of Digital Library and Open Access Approaches on Reading Comprehension}

The results (Table 2) indicated that the Open Access group outperformed the Digital Library group (9.17 vs. 8.96) on the pretest mean scores of English reading comprehension test. The result of the posttest indicated that the Digital Library group had the higher mean posttest score (11.69) than the Open Access group (10.23). Also, the gain scores illustrated that the Digital Library group had the higher mean gain scores (2.73) than the Open Access group (0.52).

Table 2. Differences in English reading comprehension between digital library and open access users

\begin{tabular}{|c|c|c|r|r|r|}
\hline Group & \multicolumn{2}{|c|}{ Pretest } & \multicolumn{2}{c|}{ Posttest } & Difference \\
\hline & Mean & SD & Mean & SD & \\
\hline Digital Library & 8.96 & 3.08 & 11.69 & 2.61 & 2.73 \\
\hline Open Access & 9.17 & 3.36 & 10.23 & 2.86 & 0.52 \\
\hline
\end{tabular}

The ANCOVA result (Table 3) showed that there was a significant difference on the post-scores between two groups after controlled for the difference of pretest $[F(1,95)=14.73$, $\mathrm{p}<.05]$. The strength of relationship between the intervention and dependent variable was moderately large, as assessed by partial Eta squared, with the intervention factor accounting for $13.4 \%$ of the variance of the dependent variable, holding constant the grades of pretest (Partial $\eta 2=.134)$.

Table 3. ANCOVA for English reading comprehension test

\begin{tabular}{|l|l|l|l|l|l|l|}
\hline Source & SS & Df & MS & F & Sig. & Partial $\eta 2$ \\
\hline Pretest & 10171.27 & 1 & 10171.27 & 80.30 & .000 & .458 \\
\hline Group & 1865.38 & 1 & 1865.38 & 14.73 & .000 & .134 \\
\hline Error & 12032.61 & 95 & 126.66 & & & \\
\hline Total & 389104.94 & 98 & & & & \\
\hline
\end{tabular}

Since the results showed that the learning performances of the Digital Library group and Open Access group were significantly different, It is concluded that digital library activities enhance students' English reading comprehension abilities. This statistical finding was supported by other researchers such as Wu and Witten (2007), Marchionini \& Maurer (1995), and Fitzgerald (2007) who identified many advantages in using digital libraries for language teaching and learning. These researchers argued that learners supported by a digital library can acquire knowledge of a subject and improve their language ability at the same time. 
Teachers can access information from the digital libraries and turn into meaningful language exercises, which can engage learners locating appropriate materials, exposing to contemporary language usage, and using proper tools to study independently.

\subsection{The Influence of Digital Library and Open Access Approaches on Learning Attitude}

The second research question investigated whether a difference exists in learning attitude when different resources were used as learning support with inquiry process. Based on the descriptive results (Table 4), students in the Digital Library group (Mean= 38.57) had higher scores on learning attitude than those in the Open Access group (Mean= 35.59). The mean rating on each survey question is presented in the Table 5. The findings revealed very positive responses from the participating students who were in the Digital Library group. Overall, on each survey question, students in the Digital Library group had higher mean attitude scores than those in the Open Access group.

Table 4. Attitude survey scores for digital library and open access groups

\begin{tabular}{|l|l|l|l|}
\hline Group & \multicolumn{2}{|l|}{ Attitude Scores } & \\
\hline & N & Mean & SD \\
\hline Digital Library & 51 & 38.57 & 4.50 \\
\hline Open Access & 47 & 35.59 & 7.18 \\
\hline
\end{tabular}

Table 5. Attitude toward instruction by the digital library and open access groups

\begin{tabular}{|c|c|c|c|}
\hline Questions & & $\mathrm{M}$ & $S D$ \\
\hline \multirow{2}{*}{$\begin{array}{l}\text { I gained English language skills using this } \\
\text { instructional approach. }\end{array}$} & Digital Library & 3.35 & .522 \\
\hline & Open Access & 3.26 & .736 \\
\hline \multirow{2}{*}{$\begin{array}{l}\text { I gained content area knowledge about the } \\
\text { topics using this instructional approach. }\end{array}$} & Digital Library & 3.61 & .532 \\
\hline & Open Access & 3.26 & .765 \\
\hline \multirow{2}{*}{$\begin{array}{l}\text { I learn to make a plan to allow enough time } \\
\text { to accomplish the tasks using this } \\
\text { instructional approach. }\end{array}$} & Digital Library & 3.53 & .578 \\
\hline & Open Access & 3.32 & .726 \\
\hline \multirow{2}{*}{$\begin{array}{l}\text { I gained a deeper understanding of the } \\
\text { concept when involving in the activities. }\end{array}$} & Digital Library & 3.33 & .516 \\
\hline & Open Access & 3.23 & .786 \\
\hline \multirow{2}{*}{$\begin{array}{l}\text { I learn research skills using this instructional } \\
\text { approach. }\end{array}$} & Digital Library & 3.53 & .504 \\
\hline & Open Access & 3.17 & .761 \\
\hline \multirow{2}{*}{$\begin{array}{l}\text { Learning English through using this } \\
\text { instructional approach was interesting. }\end{array}$} & Digital Library & 3.24 & .428 \\
\hline & Open Access & 3.11 & .667 \\
\hline \multirow{2}{*}{$\begin{array}{l}\text { The instruction had increased my motivation } \\
\text { to learn English. }\end{array}$} & Digital Library & 3.49 & .543 \\
\hline & Open Access & 3.23 & .729 \\
\hline \multirow{2}{*}{$\begin{array}{l}\text { The approach made English learning } \\
\text { meaningful. }\end{array}$} & Digital Library & 3.52 & .543 \\
\hline & Open Access & 3.09 & .717 \\
\hline \multirow{2}{*}{$\begin{array}{l}\text { Overall, I thought that taking part in the } \\
\text { activities helped me to gain confidence in } \\
\text { my own English language ability. }\end{array}$} & Digital Library & 3.53 & .542 \\
\hline & Open Access & 3.21 & .806 \\
\hline
\end{tabular}


The independent-samples t-test results (Table 6) revealed that there was a significant difference in the responses between two groups in the measure of learning attitude [ $\mathrm{t}(96)$ $=2.48, p=0.015]$. Students in the Digital Library group $(\mathrm{M}=38.57, \mathrm{SD}=4.50)$ on the average had better learning attitude toward the intervention training program than did the Open Access group $(\mathrm{M}=35.59, \mathrm{SD}=7.18)$. The results in this aspect of the study are consistent with the findings of many other studies (Recker et al., 2005; Thong, Hong, \& Tam, 2004). In general, researchers have revealed participants were very positive and enthusiastic about the value and the quality of the discovered learning resources of digital libraries. It can be reasoned that using digital libraries was easier in terms of obtaining relevant information and understanding the materials. Therefore, it is a natural next step for students to reflect the concepts or ideas that they learned from their reading activities, which in turn, made the learning meaningful and enhanced the students' learning with more positive attitude.

Table 6. Independent samples $t$ test results for attitude between digital library and open access users

\begin{tabular}{|c|c|c|c|c|}
\hline Group & Source & $d f$ & $t$ & $P$ \\
\hline Digital Library vs. Open Access & Attitude Score & 96 & 2.48 & 0.015 \\
\hline
\end{tabular}

It is important for students to learn with technologies to facilitate learning as meaning-making processes in an enlightenment way of thinking. Without a considerable investment of time and energy, these processes and skills can not be developed. Therefore, two open-ended questions were asked concerning the total hours students spent locating information and total resources they used for completing the assignments. The results (Table 7) showed that students in the Digital Library group on the average spent more time $(\mathrm{M}=2.92, \mathrm{SD}=1.49)$ and used more resources $(\mathrm{M}=3.51, \mathrm{SD}=1.71)$ doing their assignment than those in the Open Access group (Time: $\mathrm{M}=1.34, \mathrm{SD}=1.17$; Resources: $\mathrm{M}=2.04, \mathrm{SD}=1.53$ ).

Table 7. Time spent and resources used between digital library and open access users

\begin{tabular}{|l|c|c|c|c|}
\hline Group & \multicolumn{2}{|c|}{$\begin{array}{c}\text { Open Access } \\
\text { Mean }\end{array}$} & \multicolumn{2}{c|}{ Digital Library } \\
\hline & Mean & SD & Mean & SD \\
\hline Time & 1.34 & 1.17 & 2.92 & 1.49 \\
\hline Resources & 2.04 & 1.53 & 3.51 & 1.71 \\
\hline
\end{tabular}

The findings in this aspect may reason that if the participants were more positive and enthusiastic about the value and the quality of the discovered learning resources, it was easier to engaged learners going beyond simply reading a single resource as solutions for their learning tasks. As their willingness to invest time and efforts in a task increased, their motivation to search different information resources in order to observe phenomena from diverse perspectives increased as well. On the contrary, if the participants were frustrated by the wealth of available information, the negative experience of locating information may reflect on individual's willingness to invest time and efforts in a task. They might lack the motivation to search and read multiple resources following inquiry process in order to successfully achieve the task. 


\section{Implications}

This study provided evidence that a structured approach to accessing digital libraries can improve inquiry learning process, better than traditional open access to information. While reading or searching for information stored in other search engine such as Google or Yahoo, an abundance of misinformation can make confusion between what is enduring and what is ephemeral especially when learners have poor critical thinking training. Effective use of educational digital libraries as an activity focuses on finding the most appropriate resources that are relevant to individual's goals, interests, and current knowledge in order to develop domain knowledge and thinking skill, can bring interesting content topics into the language classroom. EFL teachers can design meaningful tasks and activities effectively to stimulate students to think critically through introducing the worldview and alternative points of reference from multiple resources using a well-structured digital library as a teaching and learning tool.

A well-designed and organized digital library can benefit inquiry learning process more than unstructured distributed resources. It is more difficult for learners to follow the constructive process of inquiry supported by unorganized resources to have the experience of extensive exploration of ideas and formulation of thoughts before developing their own deep understanding of the topics and presenting it. In contrast, when learners used organized digital resources stored in digital libraries for learning, the effectiveness of the inquiry process was increased by avoiding learning disorientation and cognitive loading. They become involved in thinking processes to evaluate whether the final project shows insight, depth and understanding connected with the topic. To support the implementation of inquiry-based learning, an organized repository of resources, a digital library, can provide numerous high quality of resources for information gathering with confidence which is over the advantage of other open resources.

For further research of this study, the researcher suggests enhancing the model of inquired ISP by imposing the stage of Validation between the stages of Collection, and Presentation. The original model consist six stages: Initiation, Selection, Exploration, Formulation, Collection, and Presentation. However, as more and more people rely on Internet information despite evidence that it is potentially inaccurate and biased, a process to consider the credibility of web-based information is needed.

\section{Conclusion}

The study identified the value of an organized digital library in supporting and improving EFL student's inquiry learning process. The findings showed that Taiwanese university EFL learners' test scores of English reading comprehension increased significantly from pretest to posttest in the Digital Library group than in the Open Access group. In addition, students in the Digital Library group had better learning attitudes toward the intervention-training program than did the Open Access group. We argue that online digital libraries resources have the advantage of being a basis for inquiry-based language learning and therefore facilitate English reading comprehension. EFL educators should adopt training strategies that engage learners in every stage of inquiry process, from identifying a topic and selecting what to investigate, to formulating a focused perspective and presenting their final product. 


\section{References}

Anderson, N. J. (2003). Active skills for reading: Book 1. Boston, Mass: Thomson/Heinle.

Bush, M. D., \& Terry, R. M. (1997). Technology-enhanced language learning: National Textbook Company.

Chen C. M., \& Chen C. C., (2010). Problem-based learning supported by digital archives: Case study of Taiwan Libraries History Digital Library. The Electronic Library, 28(1), 5-28. http://dx.doi.org/10.1108/02640471011005414

Chu, H. C., Hwang, G. J., Huang, S. X., \& Wu, T. T. (2008), A knowledge engineering approach to developing e-libraries for mobile learning. The Electronic Library, 26, 3-17. http://dx.doi.org/10.1108/02640470810879464

Ferguson, C. D., \& Bunge, C. A. (1997). The shape of services to come: value-based reference service for the largely digital library. College Research Libraries, 58(3), 253-255. http://dx.doi.org/10.5860/crl.58.3.252

Fitzgerald, A. (2007). Application for digital libraries in language learning and the professional development of teachers. ECDL 2007, 579-582

Goh, D. H., Ang, R. P., Theng, Y. L., \& Lim, E. P. (2005). GeogDL: a web-based approach to geography examination revision. Computers \& Education, 45(1), 57-73. http://dx.doi.org/10.1016/j.compedu.2004.04.011

Gunn, H. (2002). Virtual libraries supporting student learning. School Libraries Worldwide, 8, 27-37.

Hung, P. Y. (2008). The effects of exchanging emails with American key pals on Taiwanese college students' writing in English. Ph.D. dissertation, Kent State University, United States -Ohio. Retrieved December 2, 2010, from Dissertations \& Theses: Full Text.(Publication No. AAT 3279481).

Jayawardana, C., Hewagamage, K. P., \& Hirakawa, M. (2001). Personalization tools for active learning in digital libraries. MC Journal: The Journal of Academic Media Librarianship, 8(1).

Kastens, K. (2005). The DLESE Community Review System: Gathering, aggregating, and disseminating user feedback about the effectiveness of Web-based educational resources. Journal of geoscience education, 53(1), 37-43.

Kuhlthau, C. (1997). Learning in digital libraries: An information search process approach. Library Trends, 45, 708-724.

Kuhlthau, C. C. (2010). Guided inquiry: School libraries in the 21st century. School Libraries Worldwide, 16(1), 1-12.

Leazer, G. H., Gilliland-Swetland, A. J., \& Borgman, C. L. (2000). Evaluating the use of a geographic digital library in undergraduate classrooms: ADEPT. Paper presented at the 
Proceedings of the fifth ACM conference on Digital libraries. http://dx.doi.org/10. $1145 / 336597.336682$

Liaw, M. (2007). Content-based reading and writing for critical thinking skills in an EFL context. English Teaching and Learning, 31(2), 45-87.

Lougheed, L., \& Barron's Educational Series, Inc. (2006). Barron's TOEIC: Test of English for International Communication. Hauppauge, N.Y: Barron's

Marshall, B. B., Chen, H., Shen, R. and Fox, E.A. (2006), Moving digital libraries into the student learning space: the GetSmart experience. ACM Journal of Educational Resources in Computing, 2(1), 1-20.

Marchionini, G. and Maurer, H. (1995). The roles of digital libraries in teaching and learning. Communications of the ACM, 38(4), 67-75. http://dx.doi.org/10.1145/205323.205345

Mikulecky, L. J. (2007). Using Internet-based children's literature to teach EFL.The Internet TESL Journal, 13(11), 1-8.

Recker, M., Dorward, J., Dawson, D., Halioris, S., Liu, Y., Mao, X., et al. (2005). You can lead a horse to water: teacher development and use of digital library resources. Paper presented at the Proceedings of the 5th ACM/IEEE-CS joint conference on Digital libraries.

Russell, K. (1998). CEDARS: long-term access and usability of digital resources - the digital preservation conundrum. Ariadne, 18, Retrieved from www.ariadne.ac.uk/issue18/ cedars/

Sharifabadi, S. R. (2006). How digital libraries can support e-learning. Electronic Library, 24(3), 389-401. http://dx.doi.org/10.1108/02640470610671231

Sumner, T., \& Marlino, M. (2004). Digital libraries and educational practice: a case for new models. Paper presented at the Digital Libraries, 2004. Proceedings of the 2004 Joint ACM/IEEE Conference.

Thong, J. Y. L., Hong, W., \& Tam, K. Y. (2004). What leads to user acceptance of digital libraries? Communications of the ACM, 47(11), 78-83. http://dx.doi.org/10.1145/ 1029496.1029498

Wu, S., \& Witten, I. (2006). Towards a digital library for language learning. Research and Advanced Technology for Digital Libraries, 341-352. http://dx.doi.org/10.1007/ 978-3-540-77094-7_54

Wu, S., \& Witten, I. (2007). Content-based language learning in a digital library. Asian Digital Libraries. Looking Back 10 Years and Forging New Frontiers, 424-433.

\section{Copyright Disclaimer}

Copyright reserved by the author(s).

This article is an open-access article distributed under the terms and conditions of the Creative Commons Attribution license (http://creativecommons.org/licenses/by/3.0/). 